\title{
Changes in wellbeing: Complementing a psychosocial approach with neurobiological insights
}

\author{
Rickard, N. S\#. \& Vella-Brodrick, D. A.
}

\section{\# Corresponding author:}

A/Prof Nikki S. Rickard (corresponding author)

School of Psychology \& Psychiatry, Monash University

ph: +61-3-9903 $2221 \quad$ fax: +6139905 3948

email: nikki.rickard@monash.edu

Dr Dianne Vella-Brodrick

Melbourne Graduate School of Education

University of Melbourne

Email: Dianne.vella-brodrick@unimelb.edu.au

\begin{abstract}
The sustainability of changes in well-being achieved via positive interventions is challenged by findings that happiness levels are constrained by a homeostatic set-point. In this paper, we propose that while generally stable, the neurological and psychophysiological bases of wellbeing demonstrate plasticity. The neurobiological underpinnings of the hedonic component of
\end{abstract}


well-being are first reviewed, demonstrating the value of both central (such as frontal asymmetry) and peripheral (such as heart rate variability) indices. Convergent evidence that certain well-being interventions are capable of modifying subjective, central and peripheral indices of positive affect or regulation of negative affect is then reported, although there is a clear need for longitudinal research to demonstrate the longevity of changes. It is recommended that a multi-level approach to evaluating positive interventions incorporating subjective psychosocial and neurobiological indices of affective change is adopted by researchers in an attempt to identify interventions most likely to achieve sustained positive outcome. Accumulating evidence through rigorous research that positive interventions can enhance psychosocial and neurophysiological factors can provide a compelling case for more widespread dissemination through public health policy. 


\section{Changes in well-being: Complementing a psychosocial approach with neurobiological insights}

The assumption that subjective well-being is amenable to change underpins all efforts to promote better mental health and happiness. The long-term benefit of well-being interventions is however challenged by evidence that an individual's happiness and satisfaction levels tends to be fairly consistent and positively biased across the lifespan, regardless of major life events or efforts to modify them. This homeostatic-like stability has been argued to be evolutionarily adaptive and under the control of "dispositional, genetically pre-wired, neurological systems" (Cummins, 2010, p 4). Nonetheless, the scope to improve well-being remains. There is also evidence that certain interventions can impact even at the very fundamental neurophysiological substrates of well-being, which may result in more persistent improvements.

The aim in this paper is to critically evaluate the scientific and practical progress made towards promoting well-being and to identify more integrated and strategic methods for accelerating research insights and practical knowledge transfer. First, a brief overview of various well-being conceptualisations will be provided. This will be followed by a discussion about whether or not well-being is static and immune to intervention. Then a range of approaches and interventions for enhancing well-being will be evaluated to determine some of the most effective approaches and to explore other viable approaches not usually considered. The paper will conclude with some recommendations advocating a more integrated and multifaceted framework for evaluating and promoting well-being and will endorse inclusion of neurobiological approaches in this endeavour. 


\section{Defining well-being}

Within the domain of positive psychology, well-being and happiness have commonly been referred to and operationalised as "subjective well-being". According to this perspective well-being involves a cognitive assessment of satisfaction with life and affective (positive and negative) judgements, and is experienced when the positive aspects considerably outweigh the negative ones, so that pleasure is maximised and pain is minimised (Diener, 1994; Fredrickson, 2009). Similarly, neurobiological paradigms focus on affective style and emotion regulation as being indicative of well-being (Davidson, 2003, 2004a,b). Defined in these ways, well-being is closely aligned with emotional factors and the concept of hedonia. While this is a valid association, adopting such a narrow scope can exclude important eudaimonic aspects (Delle Fave, Bdrar, Friere, Vella-Brodrick \& Wissing, 2010; Keyes, 2002; Ryff, 1989; Waterman, 2008). Subsequently, more contemporary perspectives are emerging which emphasise the multidimensional nature of well-being by including additional factors such as psychological growth, positive relationships and life meaning to supplement the works on subjective well-being. Two examples of this more integrated and comprehensive approach to conceptualising well-being are the Orientations to Happiness $(\mathrm{OTH})$ framework which espouses pleasure, engagement and meaning pathways for happiness (Peterson, Park \& Seligman, 2005; Seligman, 2002) and the Complete State Model of Mental Health (Keyes, 2005, 2007) which articulates emotional, social and psychological factors as fundamental to sound mental health and flourishing. Recommendations to governments for measuring well-being via evaluations of life satisfaction, momentary mood and eudaimonia are also being espoused (Dolan \& Metcalfe, 2012). 


\section{Is 'trait' well-being pre-determined and static or can it be enhanced?}

While well-being states clearly fluctuate across the day, and in response to positive and negative life events, individuals are widely regarded to also exhibit a more general level of well-being that appears to endure despite changes in state well-being, much like a personality trait. . Happiness Set Point Theory, also known as the Dynamic Equilibrium Theory, asserts that happiness levels remain stable over time despite changes in life circumstances, even major ones (Headey, 2006). The happiness set point is thought to operate similarly to other human homeostatic systems whereby the body endeavours to maintain a predetermined level of happiness irrespective of external factors. While happiness levels may alter temporarily after significant life events, they soon return to a physiologically determined set point. This adaptation is commonly referred to as the hedonic treadmill (Brickman \& Campbell, 1971) or "homeostatic control" (Cummins, 2003). This stability has a genetic basis, with twin studies showing that genetic similarity accounts for approximately half of the variance observed in well-being and emotionality (Tellegen, Lykken, Bouchard, Wilcox, Segal \& Rich, 1988; Nes et al., 2006; Roysamb et al., 2003).

While there is some evidence to support the stability of life satisfaction and happiness (Cummins, 2003), this evidence is somewhat limited and overgeneralised. For example, a study by Brickman, Coates and Janoff-Bulman (1978) found that the happiness of 22 major lottery winners and 29 paralysis accident victims was within the normal range shortly after their major life event. However, the sample size was small restricting the generalisability of the findings, and no baseline data on happiness were collected hence, the level of change in happiness for each participant could not be established. Instead, post event happiness for these lottery winners and paralysis victims was compared with a control group of 22 participants who presumably did not collectively experience any significant positive or 
negative life events. Such a comparison does not consider within-subject variability, thus restricting the conclusions that can be drawn.

There are also pockets within the population, however, for whom well-being change is substantial. When well-being data from panel studies are examined, the variation in wellbeing across time for some individuals becomes more apparent. For example, using data from the German Socio-Economic Panel (SOEP), Headey (2006) examined 20 years of data from an initial sample of 12,541 respondents. Data were collected annually commencing from 1985. It was found that when the first five years of life satisfaction data were compared with the last five years of data resulting in a sample size of 2,843 , that $172(5.5 \%)$ of the respondents reported an increase of at least $20 \%$ in their scores, while 357 respondents (11.4\%) reported a decrease of at least $20 \%$. These changes were considered "substantial" given standard deviations of around 1.5. Analysis of this longitudinal data, in conjunction with personality data, found that over time, correlations between life satisfaction and the personality factors of extraversion and neuroticism diminished. This suggests that despite the long term stability of these personality traits, they are not able to maintain equilibrium with regard to life satisfaction. Moreover, respondents who were more extraverted and open to experience displayed the greatest gains in long term life satisfaction whereas those who were more neurotic reported the greatest reductions in long term life satisfaction. These findings prompted Headey (2006) to recommend major revisions to the set point theory to accommodate the viewpoint that some malleability in well-being is evident for some people, especially those with particular personality profiles. (Interestingly, Cummins (2012) also presents evidence that people with low baseline levels of well-being can also exhibit significant changes in well-being, but that this simply reflects a return to their homeostatic set-point). 
Diener, Lucas and Scollon (2006) have also provided several revisions to the original hedonic treadmill theory. These revisions acknowledge individual differences in adaptation based on temperament. A further point refers to the prospect of different types of well-being having different set points which may vary in the extent of their malleability. Life satisfaction has been most commonly used when exploring the notion of adaptation and a set point, however, the malleability of positive and negative emotions and of eudaimonic components of wellbeing is less well understood. Moreover, it is argued that an individual can have numerous set points, given the multifaceted nature of well-being. Essentially these revisions underscore that well-being set points can change depending on circumstances, the individual and the type of well-being under investigation.

Consistent with the changing perspectives and evidence on set point theory, is Lyubomirsky, Sheldon and Schkade's (2005) Architecture of Sustainable Change model. Although the model estimates that $50 \%$ of the variance in happiness is attributable to genetics and $10 \%$ to circumstantial factors such as socio-economic status, their model also acknowledges that $40 \%$ of one's happiness depends on the extent to which an individual engages in intentional activities aimed at fostering well-being. Such activities can be cognitive (e.g., adopting an optimistic outlook), behavioural (e.g., physical activity), or volitional (e.g., using signature strengths to help others). More recent discourse and evidence, particularly among scholars within the field of positive psychology, points to views that initiatives to enhance well-being are worthwhile, provided the right factors are targeted. The Architecture of Sustainable Change model emphasises that if well-being is to be enhanced, then deliberate attention needs to be directed towards factors which are susceptible to change. Although a number of significant correlates of well-being have been consistently identified in the literature, such as 
genetics and personality, and to a lesser extent, socio-demographic factors including gender, age, income and education, (see Diener, Suh, Lucas, \& Smith, 1999) it is difficult to alter these circumstances. Subsequently, there has been great interest in whether well-being can be enhanced by factors which are under the volition of the individual such as lifestyle determinants, emotion regulation strategies and positive interventions.

\section{Development and evaluation of Positive Interventions}

For some years now researchers have attempted to examine the effects of various strategies aimed at improving well-being. Noteworthy is Fordyce's (1977; 1983) work exploring a range of different happiness interventions in comparison to control conditions. Based on reviews of the happiness literature focusing on malleable methods rather than on personality and objective indicators of happiness, and on what worked best in Fordyce's (1977) previous research, Fordyce (1983) developed a "14 fundamentals for happiness program”. Happiness strategies in this program included socialising more, focusing on the present, being organised and adopting an optimistic mindset. Participants in the happiness program reported increased happiness compared to control participants. According to Fordyce (1983), the program fostered "the development of new behaviors and attitudes, changes in life-style, new insights and understandings, better copings with bad moods, enhancement of happy moods, to a better awareness of happiness itself” (p. 495). Fordyce's $(1977 ; 1983)$ work provided some preliminary evidence that happiness could be improved using deliberate strategies.

In more recent years, particularly with the inception of "positive psychology" additional interventions have been developed and evaluated. For example, the three good things activity, whereby individuals write down three positive things that happened during their day 
and why they think these good things occurred, the gratitude visit, which involves writing and delivering a letter to thank someone who had been kind to you in the past, and using signature strengths in a new way, which involves identifying signature strengths and using one of these in a new and different way every day for a week, were found to decrease depression and increase happiness for 3 months (gratitude visit) or 6 months (three good things and strengths use) post-intervention (Seligman, Steen, Park \& Peterson, 2005).

Similarly, Sheldon and Lyubomirsky (2006) found support for the best possible self activity which involves imagining yourself in the future, after everything has gone as well as it possibly could and imagining what this would be like. Numerous other well-being interventions focused on forgiveness (Reed \& Enright, 2006), kindness (Otake et al., 2006) and life coaching (Green, Oades \& Grant, 2006) have also been undertaken with many showing favourable outcomes (e.g., increased hope, positive affect, satisfaction with life and decreased depression).

Sin and Lyubomirksy's (2009) meta-analysis summarises the efficacy of 51 different positive psychology interventions (PPIs; $\mathrm{N}=4,266$ ) including mindfulness (Bédard, Felteau, Mazmanian, Fedyk, Klein, Richardson et al., 2003), positive writing (King, 2001) and WellBeing Therapy (Fava et al., 1998). Essentially this meta-analysis found that PPIs are effective in increasing well-being and decreasing depression with effect sizes of .29 and .31 , respectively. This demonstrates that although effects are not very strong and tend to be limited to short-term assessments, substantial progress is being made with the development of well-being interventions and as greater awareness is gained regarding individual difference factors, interaction effects and underlying mechanisms, more refined and robust positive 
psychology interventions can be developed. Of particular interest is the claim by Cummins (2012) that PPIs are only effective in shifting trait well-being for those who exhibit below average levels initially. According to this view, PPIs are simply facilitating a biological disposition to return to the individual's set-point.

The investigation of neurobiological mechanisms underlying various aspects of well-being may provide significant insight into the efficacy, or otherwise, of positive interventions. As with all subjective states, well-being rests on biological foundations. Importantly, the homeostatic 'set-point' hypothesized by Cummins (2003) has a biological basis, and therefore if significant changes occur at that level, we suggest that the set-point should be theoretically capable of undergoing a permanent shift. Such a fundamental shift can be likened to the persistent change that can occur in resting heart rate following a sustained physical exercise regime, and is not unusual in physiological systems. Attempts to modify well-being would therefore be well-informed by a consideration of biological mechanisms supporting this subjective state. The success or otherwise of positive psychology or lifestyle interventions will ultimately depend on the plasticity of these systems; if the neurobiological substrates underlying well-being are not malleable, then attempts to modify them may be futile. In contrast, an understanding of the mechanisms underlying well-being will help identify those interventions which have an impact on these substrates, and consequently interventions that may have greater longevity over time. In the following sections, some of the key neurobiological mechanisms associated with well-being will be described. The neurobiological profiles of affective styles and emotion regulation processes will be reviewed, and the stability of these mechanisms examined to shed light on the malleability of these substrates. Such findings provide insight into the neuroplasticity of well-being, but also 
raise the possibility that interventions might be able to target malleable substrates to deliver more powerful outcomes.

\section{Stable neurobiological patterns underlying well-being}

The majority of research into the neurobiological bases of well-being has explored subjective well-being or hedonic constructs, such as affective style, core affect, regulation of positive and negative affective states, and pleasure and reward, all of which shape global well-being. Affective style is a relatively stable disposition which refers to an individual's general emotional reactivity and regulation (Davidson, 2004). Affective disposition (or 'homeostatically protected mood') is also one of the key components determining the 'setpoint' in Cummins' homeostatic model of well-being (Cummins, 2012; Cummins, Gullone \& Lau, 2003). Individuals with a positive affective style show a tendency to approach and respond to positive stimuli with positive emotions, and to recover from negative events more quickly than do individuals with a negative affective style. Emotion regulation is one of the core means of optimising well-being; for instance, positive affect can be maintained by savouring positive emotions (Bryant \& Veroff, 2007), while negative affect can be reduced by suppression or reappraisal (Gross, 2008; Quoidbach, Berry, Hansenne \& Mikolajczak, 2010).

Biologically, regulation of emotions is a means of being flexible in the face of environmental demands (Thompson, 1994). Perceived dangers trigger basic emotions, such as fear and anger, which initiate a protective survival response (withdrawal or approach, respectively) (Davidson, Ekman, Saron, Senulis \& Friesen, 1990; Davidson, 1993). Physiologically, this translates to activation of the 'fight-flight' response, driven by sympathetic nervous system 
activity. While this 'default mode' optimizes survival from an evolutionary perspective, it is also costly in terms of energy use (Thayer \& Lane, 2009) and can be detrimental to wellbeing. Many situations involving novelty or change will also trigger this response, despite no real risk to the individual (Davidson et al., 2000). The capacity to down-regulate the full emotional response to such stimuli is thus beneficial, enabling greater flexibility in the behavioural repertoire of responses to the environment. In contrast, there is also the potential to amplify emotional responses that serve important functions. For example, life experiences which trigger positive responses can be savoured in the present or stored as a source of coping for use in challenging times or as a means to reignite and appreciate the positive experience in the future. Also of note is that some regulation strategies are likely to be more adaptive than others. For example, cognitive reappraisal strategies tend to be positively associated with well-being, while suppression of emotional expression has been negatively associated with well-being (Gross \& John, 2003; Haga, Kraft \& Corby, 2009).

\section{Central measures of well-being:}

A network of brain regions has been implicated in affective style and emotion regulation, consisting of prefrontal cortex (including dorsolateral, ventrolateral and ventromedial prefrontal cortex, and orbitofrontal cortex), insula and anterior cingulate cortex (ACC). These distributed regions have strong connections with subcortical regions, consisting of the limbic system (including the amygdala and hippocampus), basal ganglia (including the nucleus accumbens), thalamus and reticular activating system (Davidson et al.,2003; Davidson 2000; see also Figure 1). They also overlap with the cortical circuitry underlying the subjective experience of pleasure, which includes the orbitofrontal cortex, the ACC and the insular (Kringelbach \& Berridge, 2009), as well as key pathways such as the median forebrain bundle (Hernandez et al, 2006). 


\section{INSERT FIGURE 1 ABOUT HERE}

One of the most consistently reported neurobiological profiles associated with well-being is an asymmetry in prefrontal cortex (PFC) activity. Initially, stroke patients with damage to their left PFC were observed to be more likely to experience extreme anxiety and depression than comparable right lesion patients (e.g, Robinson \& Sztela, 1981; Starkstein, Robinson \& Price, 1987). This phenomenon, known as a 'catastrophising' effect, implied that the experience of positive affect may depend on a module located in the left PFC. Similarly, an 'indifference reaction' was observed more often in patients with right PFC lesions, which implied a right hemisphere based PFC module for negative affect. A similar asymmetry in emotional function is observed following temporary anesthetization of each hemisphere via sodium amytal injections (Lee, Loring, Meader \& Brooks, 1990).

There is now a large corpus of research using electroencephalographic methods which supports an association between frontal asymmetry and positive affect and well-being. For instance, Tomarken, Davidson, Wheeler and Doss (1992) recorded brain activity from 90 undergraduate females over three weeks. They found that a left bias asymmetry was positively associated with a stable positive affective style, and inversely associated with negative affect. For participants whose asymmetry was stable over this period, a left bias asymmetry was also associated with a stronger emotional response to positive films, while a right bias asymmetry was also associated with a stronger emotional response to negative films (Wheeler, Davidson \& Tomarken, 1993). Individuals with higher baseline left prefrontal activity are also more effective at voluntary suppression of emotional responses to 
negative pictures (Jackson et al.,2000). Davidson and colleagues have similarly shown that a resilient affective style is associated with greater activity in the left PFC (Davidson et al., 2000; Davidson, 2004a; Davidson \& Irwin, 1999). In contrast, individuals with greater right frontal activation show stronger reactivity to negative film clips than their left frontal counterparts. This association between frontal asymmetry and emotional responses has been observed in infants as young as four months of age (Fox, 1994), and was predictive of approach or withdrawal behaviours 10 months later. More specifically, four year olds with increased left frontal activity were more likely to be sociable in group settings, while children with reduced left frontal activation were more likely to be inhibited (Fox et al., 1995).

It has been proposed that the left PFC is involved in approach-related, goal-directed planning of actions, while right PFC activation might relate to threat-related vigilance (Davidson et al., 1990; Davidson et al., 2003; Davidson, 2004b; Kinsbourne, 1978). Importantly, Fox (1994) provides evidence that individual differences in trait affect may arise from either hyper- or hypo-activation of either hemisphere. The finding that people with left-sided prefrontal asymmetry report higher levels of positive affect and well-being (Davidson, 2004; Ochsner et al., 2002) could therefore result from greater activation of left frontal cortex or reduced activity in right frontal cortex. Several meta-analyses have confirmed that greater left PFC activation underlies positive affect or approach-related emotions (Murphy, Nimmo-Smith \& Lawrence, 2003; Wager, Phan, Liberzon \& Taylor, 2003). For instance, Wager et al. (2003) found a trend towards greater left lateralization in the lateral frontal cortex (activation peak counts: 26 left, 14 right, $\mathrm{p}<.01$ ) for approach-related emotions. Similarly, Murphy et al. (2003) found left lateralization for approach related emotions, but for whole brain rather than frontal regions (activation peak counts: 165 left, 134 right; $\mathrm{p}<.05$ ). Interestingly, this asymmetry may be moderated by sex, with some evidence for stronger left-bias asymmetry in 
men than in women (Flores-Gutierrez et al., 2009; Wager et al., 2003). In sum, individuals who show a left bias in frontal asymmetry are likely to report higher scores on subjective well-being scales, show more positive affect generally and in response to positively valenced stimuli, and tend to be approach- rather than withdrawal-oriented than do people with a right bias (Coan \& Allen, 2004; Fox, 1991; Harmon-Jones \& Allen, 1997; Jacobs \& Snyder, 1996; Sutton \& Davidson, 1997; Tomarken et al.., 1992; Wheeler et al., 1993). Conversely, individuals with greater left frontal activation should exhibit resilience in response to aversive events or stimuli. Whether this relationship means that frontal asymmetry can be directly targeted to effect changes in positive affect is an exciting possibility, and is explored further in a later section in this review.

Frontal regions of the brain are also implicated in well-being through emotion regulation. In particular, there is evidence that frontal cortical regions such as the PFC and ACC are responsible for top-down regulation of activity in subcortical limbic structures, such as the amygdala (Davidson, 2004; Fox, 1994; Gross, 2008; LeDoux, 1996; Ochsner \& Gross, 2004; Quirk et al., 2003). Greater activity in these regions results in inhibition of basic emotional responses, and predicts quicker recovery from aversive events (Davidson and colleagues, 2000, 2004). In support, people reporting higher well-being show greater activation of the ACC and reduced amygdala activation in response to negative images (van Reekum et al., 2007). Recent studies have also found that the dorsal ACC was larger (Giuliani et al., 2011) and several prefrontal regions were more active (Urry et al., 2009) in people who used an adaptive emotion regulation strategy (reappraisal). In contrast, amygdala activity increases in participants who are instructed to consciously maintain or prolong their (negative) emotional response to aversive pictures (Schaefer et al., 2002). Consistent with prefrontal asymmetry 
observations, individuals characterized by negative effect (e.g., depression) show asymmetry in amygdala activation with a right amygdala bias (Davidson et al., 2000).

\section{Peripheral measures of well-being:}

A positive affective style also involves cortical regulation of the body's homeostatic systems; the hypothalamic-pituitary axis, the sympathetic nervous system and the immune system. In their meta-analysis, Pressman and Cohen (2005) found evidence that trait positive affect was associated with reduced release of stress hormones, such as cortisol, adrenaline and noradrenaline, and enhanced immune function. One of the targets of amygdala activation during aversive conditions is the hypothalamic pituitary axis, in which cortisol is released from the adrenal glands. Individuals with a positive affective style have been found to have lower basal cortisol levels than those with a negative affective style (Cohen, Doyle, Turner, Alper \& Skoner, 2003; Davidson et al., 2000, 2004; Polk, Cohen, Doyle, Skoner \& Kirschbaum, 2005; but see also Ryff, Singer \& Dienberg Love, 2004). Similarly, individuals who are poor at regulating their emotions (in response to aversive images, despite training in suppression or reappraisal of their emotional response) exhibited abnormally high cortisol levels in the evening (Urry et al., 2006). In contrast, release of cortisol and time taken for blood pressure to return to baseline levels following a stressor were found to be reduced in individuals with a positive affective style (Bostock, Hamer, Wawrzyniak, Mitchell \& Steptoe, 2011). A range of factors thought to impact on emotion regulation (including personal control, self-soothing behaviour and social companionship) have also been associated with lowered cortisol release in children (see Stansbury \& Gunnar, 1994). 
One of the functions of cortisol is to suppress the immune system, so it is not surprising that individuals with a negative affective style also show a suppressed immune response (Rosenkranz et al., 2003). In contrast, individuals with a positive affective style showed an enhanced immune response to viruses (Cohen et al., 2003; Davidson et al., 2000, 2004; Diener \& Chan, 2011; Friedman, Hayney, Love, Singer \& Ryff, 2007; Lyubomirsky, King \& Diener, 2005). For instance, Cohen et al. (2003) exposed 334 volunteers to two rhinoviruses which produce the common cold, and assessed symptoms five days later. They found that participants reporting a more positive emotional style were dose-dependently less likely to develop disease symptoms than were participants with lower positive emotional style. Further, Kang et al. (1991) found suppressed immune function (natural NK cell activity) in women with strong right prefrontal asymmetry, suggesting the relationship between positive affective style and immune function is mediated by prefrontal asymmetry.

Emotion regulation is also reflected in cortical control of cardiovascular activity (Bernston, Quigley \& Lozano, 2007; Thayer \& Lane, 2009). Heart rate variability (HRV) is the degree to which the intervals between heart pulses vary. This variability is the result of a balance between sympathetic (which increases the heart rate) and parasympathetic (which decreases the heart rate) nervous systems, and reflects the flexibility of the cardiovascular system to changing demands (Beauchaine, 2001). A flexible autonomic nervous system is thought to be required for the appropriate expression and regulation of emotional responses (Thayer \& Lane, 2009), and HRV provides a simple, direct measure of this capacity.

Individuals with a low resting HRV are thought to have difficulty adapting to changes in the environment, and regulating their emotions (Beauchaine, Gatzke-Kopp \& Mead, 2007; Lane 
et al., 2009; Thayer \& Lane, 2009). HRV is reduced in affective disorders, such as anxiety and depression (Freidman \& Thayer 1998a, b; Kemp et al., 2010; Thayer, Friedman, Borkovec, Johnsen \& Molina, 2000; Thayer \& Lane, 2000). HRV has also, however, been associated with affective style in non-clinical populations. For instance, Bleil et al. (2008) operationalized trait 'negative affect' as the variance shared across depressed, anxious and angry emotions. They assessed 653 individuals from a community sample and found that negative affect was inversely related to the high frequency component of $\mathrm{HRV}$, which reflects parasympathetic control. In contrast, a higher resting HRV has been associated with greater emotional expressivity. For example, Butler, Wilhelm and Gross (2006) assessed respiratory sinus arrhythmia (RSA), which equates with the high frequency band of the HRV when respiration rate is controlled, and thus indicative of parasympathetic regulation of the heart period, in a sample of women. They found that a high resting RSA was associated with greater emotional expressivity in discussing a distressing video (as measured by video recordings of both verbal and non-verbal expressions). Shook et al. (2007) demonstrated that individuals with a higher resting HRV showed a greater willingness to approach positive novel objects, and were less likely to attend extensively to negative objects, than people with a lower resting HRV.

Individuals with a higher resting HRV also demonstrated more appropriate emotion regulation of the eyeblink startle response (Melzig, Weike, Hamm \& Thayer, 2009; RuizPadial, Sollers, Vila \& Thayer, 2003). The reflex eyeblink response to a loud noise is exaggerated under negative affective conditions, and reduced under positive affective conditions. Melzig et al. (2009) potentiated the eyeblink response by threatening participants with shock, and found that it returned to baseline more quickly following a loud noise in participants with high HRV than in participants with low HRV, implying that the latter were 
less able to regulate their anxiety. Ruiz et al. (2003) found that participants with low HRV showed greater startle magnitudes to both negative and neutral stimuli, which they interpret as reflecting poor prefrontal cortical control of the amygdala-mediated defence system. In support, Lane et al. (2001) found that HRV was associated with activity in the medial PFC, which suggests that HRV may also be an indirect index of PFC-governed emotion regulation.

\section{Different aspects of well-being:}

The debate regarding how hedonic and eudaimonic well-being should be conceptualized is ongoing (Biswas-Diener, Kashdan \& King, 2009). The neurobiological literature can potentially provide insight into this ambiguity by exploring whether there are distinct neurobiological profiles for these constructs.

The majority of this work has isolated neural networks associated with hedonic well-being. For instance, a meta-analysis of imaging studies on emotion processing performed by Phan et al. (2002) found that over $70 \%$ of studies which induced happiness reported activation in the basal ganglia. Importantly, the functional neuroanatomy of these hedonic hotspots is moderated by neurotransmitters, with endorphins strongly implicated in pleasure (or 'liking') (Smith \& Berridge, 2005; Stewart \& Vezina, 1988), while dopamine appears to be more involved in desire or 'wanting' (Berridge \& Robinson, 1998; Kringelbach \& Berridge, 2010; Wachtel et al., 2002). Cannabinoids have also been associated with pleasure, with this action likely to be mediated also by dopamine release in the mesolimbic reward regions of the brain (French, Dillon \& Wu, 1997; Lupica, Riegel \& Hoffman, 2004). A full profile of biochemical markers of well-being is yet to be established, although it is likely that they will yield differences in basal levels of transmitters implicated in pleasure, such as dopamine and 
beta-endorphins, as well as those involved in social bonding such as oxytocin and prolactin (Depue \& Collins, 1999; Panksepp, 1998; Ryff \& Singer, 1998).

To date, there are considerably fewer studies which have attempted to isolate neural underpinnings of eudaimonic well-being. Ryff and colleagues (Friedman et al., 2007; Ryff et al., 2004; Ryff et al., 2006) found a number of psychobiological indices were associated with eudaimonic well-being, measured by the Psychological Well-Being Scales (Ryff, 1989) in a sample of older women. These included lower levels of basal cortisol, higher levels of noradrenaline and lower inflammation responses as measured by pro-inflammatory cytokines. More specifically, daily cortisol patterns were flatter (meaning they remained low throughout the day) in women 75 years and over who reported strong personal growth and purpose in life. In women 65 years and older, adrenaline levels were positively associated with positive relations and noradrenaline levels were positively associated with autonomy, while inflammatory markers (interleukin-6 and soluble interleukin 6 receptors) were negatively correlated with purpose in life. Urry et al. (2004) examined neural predictors of eudaimonic (also measured by Ryff's PWBS) and hedonic well-being, measured by the Satisfaction with Life Scale (Diener, Emmons, Larsen \& Griffin, 1985) and the PANAS (Watson, Clark \& Tellegen, 1988). They found left frontal activity was correlated with both forms of wellbeing. When positive affect was controlled, psychological well-being (but not satisfaction with life) still accounted for some prediction in left frontal activity, implying that increased left frontal activation is also associated with eudaimonic well-being in a manner that extends beyond positive affect alone. 
More broadly, neurobiological concomitants have been observed for a range of constructs associated with eudaimonic well-being, including transcendence, spirituality and mindfulness. Dispositionally mindful people, for example, have been found to exhibit more effective PFC functioning during emotional categorization tasks (Creswell, Way, Eisenberger \& Lieberman, 2007). The dorsal ACC (which plays a key role in attention) is also thicker, and more active during meditation, in expert meditators than in non-meditators (Grant, Courtemanche, Duerden, Duncan, \& Rainville, 2010; Holzel et al, 2007; see also Holzel et al, 2011 for review). There have also been a number of brain regions (or 'God spots') implicated in spirituality, religiosity or transcendence, although these appear to be quite distributed (including the PFC, temporal and parietal lobe; Esel, 2009; Kapogiannis et al., 2009; Persinger, 2010; Ramachandran, Hirstein, Armel, Tecoma \& Iragui, 1997). In one recent study, Newberg, Wintering, Waldman, Amen, Khalsa and Alavi (2010) found that long-term meditators exhibited increased activation in the frontal lobes, with some evidence of left bias asymmetry. Higher pleasures, such as transcendent states, aesthetic appreciation of music and arts, altruism, and social relationships, may also be represented in identifiable brain circuits. For instance, strong emotional experiences with music activate regions that are associated with reward and emotion, including the thalamus, insula, orbitofrontal cortex and ventral striatum, and reduce activation in the amygdala and ventromedial prefrontal cortex (Blood \& Zatorre, 2001). Further, Griffiths et al. (2004) found that left hemisphere lesions to the amygdala and insula resulted in selective loss of intensely positive experiences of music, suggesting that this higher pleasure may also be reflected in a left-bias asymmetry.

In sum, there is substantial evidence for particular neurobiological profiles on which wellbeing rests. People with a positive affective style, and who are able to regulate their emotions well, show superior prefrontal inhibition of limbic system regions responsible for generating 
basic emotions. They also show lower levels of circulating and reactive cortisol than people characterized by negative affect, and appear to be immunologically resilient. Flexibility in adapting to the environment in a positive way is also reflected in a more variable heart rate, indicative of an effective balance of the parasympathetic and sympathetic nervous systems. While the data suggest that hedonic and eudaimonic well-being share some neural substrates, the possibility of distinct but overlapping networks needs to be explored with more extensive mapping. In the next section, we explore whether these neurobiological substrates of wellbeing are trait-like, or whether they can be modified significantly by interventions.

\section{Are neurobiological substrates of well-being modifiable?}

There are a number of convincing arguments supporting the flexibility of neurobiological substrates of well-being to modification. First, although there is a substantial genetic component to well-being (Nes et al., 2006; Roysamb et al., 2003; Tellegen et al., 1988; Lykken \& Tellegen, 1996), there is also considerable scope for environmental influence. Heritability of well-being is estimated to be variously 50\% (Lyubomirsky, Sheldon \& Schkade, 2005), 72\% (Keyes et al, 2005) or even 80\% (Lykken \& Tellegen, 1996). Regardless of the figure, at least $20 \%$ of the variability appears to be independent of genetic or demographic factors. For instance, while Tellegen et al. found that $40 \%$ of the variance in pleasant emotionality was accounted for by genetic similarity in twins, they also found that $20 \%$ was accounted for by family environment. Similarly, while $48 \%$ of the variance in wellbeing was inherited, $13 \%$ was a result of family environment. Similarly, while there appears to be a heritable component of frontal asymmetry, this component is relatively small (e.g., between 27 and 32\%), indicating considerable flexibility (Anokhin, Heath, \& Myers, 2006; Smit, Posthuma, Boomsma, \& de Geus, 2005). 
Second, even the heritable component of well-being is subject to environmental interaction (see Nesse, 2004). Lyubormirsky et al (2005) argue that "even a high heritability coefficient for a particular trait (such as happiness) does not rule out the possibility that the mean level of that trait for a specific population can be raised. Under the right conditions, perhaps everyone can potentially become happier." (p9). Genes code for proteins, which can direct the growth of neurons in particular brain regions, increase the receptor sensitivity to certain neurotransmitters or a range of other neurobiological events that may predispose an individual to certain traits. A number of transmitter receptor systems implicated in mood have been hypothesized to mediate the genetic contribution to well-being (Roysamb et al., 2003). For instance, a gene which codes for transport of the neurotransmitter serotonin is associated with a positive bias in attending to affective stimuli (Fox, Ridgewell \& Ashwin, 2009). This gene (5-HTT) is however subject to gene by environment interactions and therefore its expression shows considerable variability between individuals (see Caspi et al., 2010). The expression of heritable components of well-being (the well-being 'phenotype') is therefore also clearly influenced by lifestyle or volitional factors. Positive interventions could therefore theoretically provide the appropriate environmental conditions to enhance well-being, despite its strong genetic component.

Third, processes underlying well-being demonstrate both state and trait-like characteristics. Prefrontal asymmetry associated with affective style is reported to be quite reliable over time, and therefore trait-like (Davidson, 2004a). However, it is not stable for all people. In particular, children's frontal asymmetry is not reliable over time (Davidson \& Rickman, 1999), supporting a developmental basis for this substrate. A developmental basis for emotion regulation has also been well established (Goldsmith, Buss \& Lemery, 1997; 
Goldsmith, Pollak \& Davidson, 2008). Such data imply that a propensity for well-being may be consolidated early, but does not necessarily imply it is resistant to modulation later in life. Frontal brain regions involved in emotion regulation and well-being are still undergoing development well after puberty (Keverne, 2004), so the onset of interventions during childhood or adolescence may be particularly fruitful.

Neuroplasticity is well-established throughout the lifespan, and a range of enriching lifestyle activities have been found to enhance the connectivity or density of neural networks (e.g., Johansson, 2006; Kempermann et al., 2002; Merzenich, 2005, Rosenzweig \& Bennett, 1996; Scarmeas \& Stern, 2003). Substantial research also suggests that even stable asymmetries can be modified by experience. Coan and Allen (2004) found that variances in EEG asymmetry were equally attributable to trait and state effects ( 8 and $10 \%$ respectively). Most notably, a shift in prefrontal asymmetry has been observed following a range of manipulations including presentation of affective stimuli (see Coan \& Allen, 2004 for review). Even a short period of massage or uplifting music exposure was found to significantly shift right frontal asymmetry in depressed adolescents immediately postexposure (Jones \& Field, 1999). However, whether such shifts in frontal asymmetry persist beyond the treatment period is unclear as there are very few studies which have re-tested after a delay to determine longevity (see below).

Finally, there is emerging evidence of changes to these substrates following interventions in theory-consistent directions (see Pressman \& Cohen, 2005, and Coan \& Allen, 2004, for reviews). This evidence is most clear in studies which have investigated emotion regulation, mindfulness and meditation. 
Emotion regulation: One paradigm which has been effective for illustrating the effects of emotion regulation involves instructing participants to either 'enhance', 'maintain' or 'suppress' their emotional response to emotionally valenced images. Effective suppression or reappraisal of a response to negative images increases activation of left ventromedial PFC and dorsal ACC and reduces activation of the right amygdala (Ochsner et al., 2002; 2004; Ochsner \& Gross, 2005; Urry et al., 2006; Levesque et al., 2003; Goldin et al., 2008), as well as reducing the magnitude of the eyeblink startle response (Dillon \& LeBar, 2005; Jackson et al., 2000) and release of the stress hormone, ACTH (Abelson, Liberzon, Young, \& Khan, 2005). Further, participants in the enhance condition were found by Jackson et al. (2000) to experience increased eyeblink startle responses. In contrast, suppression of emotional responses to positive stimuli (erotic pictures) resulted in activation of right prefrontal regions (Beauregard, Levesque \& Bourgouin, 2001). Schaefer et al. (2002) asked participants to either maintain, regulate or be passive about their emotion response to negative pictures. Amygdala activity was greatest in the maintenance condition, although it is noted that suppression was also observed to increase amygdala activation in one study (Goldin et al., 2008).

$\mathrm{HRV}$ is also a sensitive marker of phasic changes in response to emotion regulation interventions. For example, Butler et al. (2006) instructed participants to either suppress ('act as if feel nothing'), reappraise ('look for the positive') or respond normally to an aversive film about WWII bombings. They found that both emotion regulation groups exhibited significantly higher HRV in the high frequency band than did the control participants. In addition, Lane et al. (2008) demonstrated that increases in HRV associated with emotion 
regulation are associated with activation in the ACC, a region implicated in emotion regulation (see also Matthews et al., 2004 and O’Connor, 1990).

Mindfulness/Meditation: Interventions aimed at increasing eudaimonic well-being also appear to increase left-sided frontal asymmetry, possibly by promoting emotion regulation. Davidson, Kabat-Zinn et al. (2003) randomly assigned participants to either an eight week meditation training program or a wait-list. Significant increases in left-sided anterior brain activation and immunoprotection (influenza antibody titres) were observed from baseline to post-intervention. Importantly, both the asymmetry and immunoprotection index were maintained when tested four months after the mindfulness intervention. A focussed attention meditation condition yielded increased activation in the dorsolateral PFC, an effect which was stronger in practitioners than novices (Brefczynski-Lewis, et al., 2008). In addition to emotion regulation, mindfulness also promotes attention regulation. Consistent with the role of the ACC in attention, five days of mediation results in increased activation of the rostral ACC (Tang et al, 2009). Anterior cingulate cortex white matter was also increased after 11 hours of meditative training (Tang et al, 2010).

In sum, the neurobiological circuits underlying well-being appear to exhibit considerable plasticity, even in adulthood. Interventions targeted at increasing positive affect on the whole are capable of shifting frontal asymmetry to the left, mimicking the left bias present in trait positive affective style. A consistent caveat of this research however is the absence of longitudinal studies, and therefore the persistence of effects on both well-being and its neurobiological substrates remains to be determined. Nonetheless, one study to date (Davidson, Kabat-Zinn et al., 2003) has demonstrated that mindfulness meditation causes an 
increase in left frontal asymmetry and immune functioning for at least four months after the intervention. Interestingly, two studies in which eudaimonic well-being was explored revealed a pattern of asymmetry that was more central than prefrontal (Davidson, Kabat-Zinn et al., 2003; Urry et al., 2004), which may suggest a broader neural circuitry extending beyond the prefrontal centre implicated in hedonic well-being. Peripheral markers of wellbeing, such as HRV, also appear to be influenced by interventions such as emotion regulation, which has exciting implications for physical health benefits. Overall, the findings indicate that the neural basis of well-being can be modified by interventions, which may provide useful foci for designing interventions which target these substrates. For instance, interventions which exploit left prefrontal activation, such as those which engage approach motivations, might be particularly effective (Urry et al., 2004).

\section{Conclusion}

Community and practitioner interest in cognitive and behavioural interventions which enhance well-being is expanding at a rapid rate (Seligman et al., 2005; Sin \& Lyubomirksy, 2009). It is therefore timely that empirical research on such interventions is also beginning to accelerate. Nonetheless, because of the multi-disciplinary nature of well-being, this research has been fragmented. Positive psychological interventions have tended to be evaluated quite independently of research exploring the underlying mechanisms of well-being, and the efficacy of well-being interventions is typically conceptualized via subjective and psychosocial reports quite separately from their effects on central or peripheral physiology. Clearly there is an element of multidisciplinary interdependence and expertise which when fused promises to deliver a more effective and efficient approach to facilitating individual well-being. 
By reviewing the literature on both stable and malleable physiological substrates of wellbeing, this paper highlights the importance of a neurobiological perspective to well-being intervention research. Interventions which influence emotion regulation and affective style can also influence the biological underpinnings of those processes. The importance of these findings for those in the field of health promotion is that the value or efficacy of interventions may be at least partly determined by whether they can effect measurable changes at this very fundamental level of well-being. The interventions that are most likely to yield a sustained increase in well-being over time may be those with effects that permeate down to the biological foundations of well-being, demonstrating a profound shift in affective disposition and potentially the hypothesized homeostatic 'set-point' of an individual's well-being. In contrast, interventions which appear to impact only on the phenomenology of well-being may be more difficult to sustain, and may be subject to the substantial forces of the hedonic treadmill. Subsequently, well-being scholars are encouraged to: 1) adopt a multi-level approach in their evaluations of positive psychology interventions, incorporating subjective psychosocial factors and neurobiological indices of affective change; 2) obtain assessments at multiple time-points in an effort to gauge the sustainability of well-being enhancement; and 3) aim to differentiate between various mechanisms responsible for improvements in well-being, by specifically targeting well-being processes, such as emotion regulation. Such endeavours should contribute to a significantly more systematic, integrated and collaborative approach to understanding and promoting well-being and will provide more substantial and compelling evidence necessary for influencing public health policy and creating more widespread health benefits. 



\section{References}

Abelson, J.L., Liberzon, I., Young, E.A., \& Khan, S. (2005). Cognitive modulation of the endocrine stress response to a pharmacological challenge in normal and panic disorder subjects. Archives of General Psychiatry, 62, 668-75.

Addis, D. R., Sacchetti, D. C., Ally, B. A., Budson, A. E., \& Schachter, D. L. (2007). Episodic simulation of future events is impaired in mild Alzheimer's disease. Neuropsychologia, 45, 1363-77.

Allen, J.J.B., Harmon-Jones, E., \& Cavender, J.H. (2001). Manipulation of frontal EEG asymmetry through biofeedback alters self-reported emotional responses and facial EMG. Psychophysiology 38, 685-693.

Anokhin, A.P., Heath, A.C. \& Myers E. (2006). Genetic and environmental influences on frontal EEG asymmetry: A twin study. Biological Psychology, 71, 289-295.

Beauchaine, T. (2001). Vagal tone, development, and Gray's motivational theory: Toward an integrated model of autonomic nervous system functioning in psychopathology. Development and Psychopathology, 13, 183-214.

Beauchaine, T., Gatzke-Kopp. L., \& Mead, H. (2007). Polyvagal theory and developmental psychopathology. Emotion dysregulation and conduct problems from preschool to adolescence. Biological Psychology, 74, 174-184.

Beauregard, M., Lévesque, J. and Bourgouin, P. (2001) Neural Correlates of Conscious SelfRegulation of Emotion The Journal of Neuroscience, 21, RC165:1-6

Bédard, M., Felteau, M., Mazmanian, D., Fedyk, K., Klein, R., Richardson, J. et al.. (2003). Pilot evaluation of a mindfulness-based intervention to improve quality of life among individuals who sustained traumatic brain injuries. Disability and Rehabilitation, 25, 722-731. 
Bernston, G. G., Quigley, K. S., \& Lozano, D. (2007). Cardiovascular psychophysiology. In. In: J. T. Cacioppo, L. G. Tassinary, \& G. G. Berntson (Eds). Handbook of psychophysiology (3rd Ed). Cambridge University Press, pp 193-197.

Berridge, K.C. \& Robinson, T.E. What is the role of dopamine in reward: Hedonics, learning, or incentive salience? Brain Research Reviews, 28, 308-367, 1998.

Biswas-Diener, R., Kashdan, T. \& King, L. (2009). Two traditions of happiness research, not two distinct types of happiness. Journal of Positive Psychology, 4, 208-211.

Blood, A. \& Zatorre, R. J. (2001) Intensely pleasurable responses to music correlate with activity in brain regions implicated in reward and emotion. Proceedings of the National Academy of Science USA, 98, 11818-11823

Bostock, S., Hamer, M., Wawrzyniak, A. J., Mitchell, E. S., \& Steptoe, A. (2011). Positive emotional style and subjective, cardiovascular and cortisol responses to acute laboratory stress. Psychoneuroendocrinology, 36, 1175-1183.

Brefczynski-Lewis, J.A. Lutz, A. Schaefer, H.S. Levinson, D.B. and Davidson, R.J. (2008). Neural correlates of attentional expertise in long-term meditation practitioners. Proceedings of the National Academy of Sciences USA, 104, 11483-11488.

Breiter, H.C., Gollub, R.L., Weisskoff, R.M., Kennedy, D.N., Makris, N., Berke, J.D., Goodman, J.M., Kantor, H.L., Gastfriend, D.R., Riorden, J.P., Matthew, R.T., Rosen, B.R., \& Hyman, S.E. (1997). Acute effects of cocaine on human brain activity and emotion. Neuron, 19, 591-611.

Brickman, P., \& Campbell, D. T. (1971). Hedonic relativism and planning the good society. In M. H. Appley (Ed.), Adaptation-level theory: A symposium (pp. 287-302). New York: Academic Press. 
Brickman, P., Coates, D., \& Janoff-Bulman, R. (1978). Lottery winners and accident victims: Is happiness relative? Journal of Personality and Social Psychology, 36, 917-927.

Bryant, F. B., \& Veroff, J. (2007). Savoring: A new model of positive experience. Mahwah, NJ: Lawrence Erlbaum.

Butler, E. A., Wilhelm, F. H., \& Gross, J. J. (2006). Respiratory sinus arrhythmia, emotion, and emotion regulation during social interaction. Psychophysiology, 43, 612-622.

Caspi, A., Hariri, A. R., Holmes, A., Uher, R., \& Moffitt, T. E. (2010). Genetic sensitivity to the environment: The case of the serotonin transporter gene and its implications for studying complex diseases and traits. American Journal of Psychiatry, 167, 509-527.

Coan, J. A., \& Allen, J. J. B. (2004). Frontal EEG asymmetry as a moderator and mediator of emotion. Biological Psychology, 67, 7-49.

Cohen, S., Doyle,W.J., Turner, R.B., Alper, C.M.,\&Skoner, D.P. (2003). Emotional style and susceptibility to the common cold. Psychosomatic Medicine, 65, 652-657.

Creswell, J.D., Way, B.M., Eisenberger N.I. \& Lieberman, M.D. (2007). Neural correlates of dispositional mindfulness during affect labeling. Psychosomatic Medicine, 69, 560565.

Cummins R. A. (2003). Normative life satisfaction: measurement issues and a homeostatic model. Social Indicators Research, 64, 225-56.

Cummins, R. (2010) Subjective wellbeing, homeostatically protected mood and depression : a synthesis. Journal of Happiness Studies, 11, 1-17.

Cummins, R. (2012). Positive psychology and subjective wellbeing homeostasis: A critical examination of congruence. In: A. Efklides \& D. Moraitou (Eds). Quality of life: A positive psychology perspective. New York: Springer. 
Cummins, R. A., Gullone, E., \& Lau, A.L.D. (2003) The universality of subjective wellbeing indicators. Social Indicators Research Series, 16, 7-46.

Davidson, R. J. \& Irwin, W. (1999) The functional neuroanatomy of emotion and affective style. Trends in Cognitive Sciences. 3, 11-21

Davidson, R. J. (1993). Parsing affective space: Prespectives from neuropsychology and psychophysiology. Neuropsychology, 7, 464-475.

Davidson, R. J. (2003). Affective neuroscience and psychophysiology: Toward a synthesis. Psychophysiology, 40, 655-665.

Davidson, R. J. (2004a). Well-being and affective style: neural substrates and biobehavioural correlates. Philosophical Transactions of the Royal Society, 359, 1395-411.

Davidson, R. J. (2004b). What does the prefrontal cortex "do" in affect: Perspectives in frontal EEG asymmetry research. Biological Psychology, 67, 219-234.

Davidson, R. J., \& Rickman, M. (1999). Behavioral inhibition and the emotional circuitry of the brain: Stability and plasticity during the early childhood years. In L. A. Schmidt \& J. Schulkin (Eds.), Extreme fear and shyness: Origins and outcomes (pp. 67-87). New York: Oxford University Press.

Davidson, R. J., Ekman, P., Saron, C. D., Senulis, J. A., \& Friesen, W. V. (1990) Approachwithdrawal and cerebral asymmetry: Emotional expression and brain physiology I. Journal of Personality and Social Psychology, 58, 330-341.

Davidson, R. J., Jackson, D. C., \& Kalin, N. H. (2000). Emotion, plasticity, context, and regulation: Perspectives from affective neuroscience. Psychological Bulletin, 126, 890-909. 
Davidson, R. J., Kabat-Zinn, J., Schumacker, J., Rosenkranz, M., Muller, D., Sontorelli, S. F., et al.. (2003). Alterations in brain and immune function produced by mindfulness meditation, Psychosomatic Medicine, 65, 564-570.

Delle Fave, A, Brdar, I., Freire, T., Vella-Brodrick, D., \& Wissing, M. P. (2011). The Eudaimonic and hedonic components of happiness: Qualitative and quantitative findings. Social Indicators Research, 100, 185-207.

Depue, R. A., \& Collins. (1999). Neurobiology of the structure of personality: Dopamine, facilitation of incentive motivation, and extraversion. Behavioral and Brain Sciences, 22, 491-569

Diener, E. (1994). Assessing subjective well-being: Progress and opportunities. Social Indicators Research, 31, 103-157.

Diener, E., \& Chan, M.Y. (2011). Happy people live longer: Subjective well-being contributes to health and longevity. Applied Psychology: Health and Well-Being. Doi:10.1111/j.1758-0854.2010.01045.x

Diener, E., \& Lucas, R. E., \& Scollon, C. N. (2006). Beyond the hedonic treadmill: Revising the adaptation theory of well-being. American Psychologist, 61, 305-314.

Diener, E., Emmons, R. A., Larsen, R. J., \& Griffin, S. (1985). The Satisfaction With Life Scale. Journal of Personality Assessment, 49, 71-75.

Diener, E., Suh, E. M., Lucas, R. E., \& Smith, H. L. (1999). SWB: Three decades of progress. Psychological Bulletin, 125, 276-302.

Dillon, D. G., \& LaBar, K. S. (2005). Startle modulation during conscious emotion regulation is arousal-dependent. Behavioral Neuroscience, 119, 1118-1124. 
Dolan, P., \& Metcalfe, R. (2012). Measuring subjective wellbeing: Recommendations on measures for use by national governments, Journal of Social Policy, 1, 1-19.

Eşel, E. (2009). Probable cognitive and neurobiological mechanisms of religious and mystic experiences. Bulletin of Clinical Psychopharmacology, 19, 193-205

Fava, G. A., Rafanelli, C., Cazzaro, M., Conti, S., \& Grandi, S. (1998). Well-being therapy: A novel psychotherapeutic model for residual symptoms of affective disorders. Psychological Medicine, 28, 475-480.

Flores-Gutierrez, E. O., Diaz, J-L., Barrios, F. Aavilla-Humara, R., Guevara, M. A., del RioPortilla, Y., et al.. (2007). The metabolic and electric brain patterns during pleasant and unpleasant emotion induced by music masterpieces. International Journal of Psychophysiology, 65, 69-84.

Fordyce, M. W. (1977). Development of a program to increase happiness. Journal of Counseling Psychology, 24, 511-521.

Fordyce, M. W. (1983). A program to increase happiness: Further studies. Journal of Counseling Psychology, 4, 483-498.

Fox, E., Ridgewell, A. \& Ashwin, C. (2009) Looking on the bright side: biased attention and the human serotonin transporter gene. Royal Society B, 276, 1747-1751

Fox, N. A. (1991). If it's not left, it's right. Electroencephalograph asymmetry and the development of emotion. American Psychologist, 46, 863-72.

Fox, N. A. (1994). Dynamic cerebral processes underlying emotion regulation. Monographs of the Society for Research in Child Development, 59, 152-166. 
Fox, N.A., Rubin, K.H., Calkins, S.D., Marshall, T.R., Coplan, R.J., Porges, S.W., Long, J., \& Stewart, S. (1995). Frontal activation asymmetry and social competence at four years of age. Child Development.66, 1770-1784.

French, E.D., Dillon, K., \& Wu, X. (1997). Cannabinoids excite dopamine neurons in the ventral tegmentum and substantia nigra. NeuroReport, 8, 649-652.

Friedman, B. H., \& Thayer, J. F. (1998a). Autonomic balance revisited: panic anxiety and heart rate variability. Journal of Psychosomatic Research, 44, 133-151.

Friedman, B. H., \& Thayer, J. F. (1998b). Anxiety and autonomic flexibility: a cardiovascular approach. Biological Psychology, 48, 303-323.

Friedman, E.M., Hayney, M., Love, G.D., Singer, B., \& Ryff, C.D. (2007). Plasma interleukin-6 and soluble IL-6 receptors are associated with psychological well-being in aging women. Health Psychology, 26, 305-313.

Gerson, A., Dannon, P., \& Grunhuas, L. (2003). Transcranial magnetic stimulation in the treatment of depression. American Journal of Psychiatry, 160, 835-45.

Giuliani, N. R., Drabant, E. M., \& Gross, J. J. (2011). Anterior cingulate cortex volume and emotion regulation: Is bigger better? Biological Psychology, 86, 379-382.

Goldin, P. R., McRae, K., Ramel, W., \& Gross, J. J. (2008). The neural bases of emotion regulation: Reappraisal and suppression of negative emotion. Biological Psychiatry, 63, 577-586.

Goldsmith, H. H., Buss, K. A., \& Lemery, K. S. (1997). Toddler and childhood temperament: Expanded content, stronger genetic evidence, new evidence for the importance of environment. Developmental Psychology, 33, 891-905. 
Goldsmith, H. H., Pollak, S. D., \& Davidson, R. J. (2008). Developmental neuroscience perspectives on emotion reugulation. Child Development Perspectives, 2, 132-40.

Grant, J.A., Courtemanche, J., Duerden, E.G., Duncan, G.H., \& Rainville, P. (2010). Cortical thickness and pain sensitivity in Zen meditators. Emotion, 10, 43-53.

Green, L. S., Oades, L. G., \& Grant, A. M. (2006). Cognitive-behavioural, solution-focused life coaching: Enhancing goal striving, well-being and hope. The Journal of Positive Psychology, 1, 142-149.

Griffiths, T. D., Warren, J. D., Dean, J. L., \& Howard, D. (2004). When the feeling's gone a selective loss of musical emotion. Journal of Neurology, Neurosurgery and Psychiatry, 75, 344-345.

Gross, J. J. (2008). Emotion regulation. In: M. Lewis, J. M. Haviland-Jones, and L. Feldman Barrett (Eds). Handbook of emotions (3rd Ed.). New York: The Guilford Press.

Gross, J. J., \& John, O. P. (2003). Individual differences in two emotion regulation processes: Implications for affect, relationships, and well-being. Journal of Personality and Social Psychology, 85, 348-362.

Haga, S.M., Kraft, P., \& Corby, E.K. (2009). Emotion regulation: Antecedents and wellbeing outcomes of cognitive reappraisal and expressive suppression in cross-cultural samples. Journal of Happiness Studies, 10, s 271- 291.

Harmon-Jones, E., \& Allen, J. J. B. (1997). Behavioral activation sensitivity and resting frontal EEG asymmetry: Covariation of putative indicators related to risk for mood disorders. Journal of Abnormal Psychology, 106, 159-63.

Headey, B. (2006). Life goals matter to happiness: A revision of set-point theory. Social Indicators Research, 86, 213-231. 
Hernandez G, Hamdani S, Rajabi H, et al. (2006). Prolonged rewarding stimulation of the rat medial forebrain bundle: neurochemical and behavioral consequences. Behavioral Neuroscience, 120(4), 888-904.

Hölzel, B.K., Lazar, S.W., Gard, T., Schuman-Olivier, Z., Vago, D.R., \& Ott, U. ((2011). How does mindfulness meditation work? Proposing mechanisms of action from a conceptual and neural perspective. Perspectives on Psychological Sciences, 6(6), 537559.

Hölzel, B.K., Ott, U., Hempel, H., Hackl, A., Wolf, K., Stark, R., \& Vaitl, D. (2007). Differential engagement of anterior cingulate and adjacent medial frontal cortex in adept meditators and nonmeditators. Neuroscience Letters, 421, 16-21.

Jackson, D. C., Malmstadt, J. R., Larson, C. L., \& Davidson, R. J. (2000). Suppression and enhancement of emotional responses to unpleasant pictures. Psychophysiology, 37, $515-522$.

Jacobs, G. D., \& Snyder, D. (1996). Frontal brain asymmetry predicts affective style in men. Behavioral Neuroscience, 100, 36.

Johansson, B. B. (2006). Music and brain plasticity. European Review, 14, 49-64.

Jones, N.A., \& Field, T. (1999). Massage and music therapies attenuate frontal EEG asymmetry in depressed adolescents. Adolescence 34, 529-535.

Kang, D-H., Ershler, W.B., Davidson, R.J., Coe, C.L., Wheeler, R.E. \& Tomarken, A.J. (1991). Frontal brain asymmetry and immune function. Behavioral Neuroscience, $106,860-869$.

Kapogiannis, D., Barbey, A.K., Su, M., Zamboni, G., Krueger, F., \& Grafman, J. (2009). Cognitive and neural foundations of religious belief. Proceedings of the National Academy of Sciences USA, 106, 4876-4881. 
Kemp, A.H., Quintana, D.S., Felmingham, K.L., Gray, M.A., Brown, K., Gatt, J.M. (2010). Impact of depression and antidepressant treatment on heart rate variability: A review and meta-analysis. Biological Psychiatry, 67, 1067-1074.

Kempermann, G., D. \& Gast, et al.. (2002). Neuroplasticity in old age: sustained fivefold induction of hippocampal neurogenesis by long-term environmental enrichment. Annals of Neurology, 52, 135-43.

Keverne, E.B. (2004). Understanding well-being in the evolutionary context of brain development. Philosophical Transactions of the Royal Society of London B, 359, $1349-1358$.

Keyes, C. L. M. (2002). The mental health continuum: From languishing to flourishing in life. Journal of Health and Social Research, 43, 207-222.

Keyes, C. L. M. (2005). Mental illness and/or mental health? Investigating axioms of the complete state model of health. Journal of Consulting and Clinical Psychology, 73, $539-548$.

Keyes, C.L.M. (2010). The structure of the genetic and environmental influences on mental well-being. American Journal of Public Health, 100, 2379-2385.

Keyes, C. L. M. (2007). Promoting and protecting mental health as flourishing: A complementary strategy for improving national mental health. American Psychologist, $62,95-108$.

King, L. A. (2001). The health benefits of writing about life goals. Personality and Social Psychology Bulletin, 27, 798-807.

Kinsbourne, M. (1978) Evoluation of language in relation to lateral activation. IN M. Kinsbourne (Ed.). Asymmetrical function of the brain (pp. 553-556). New York: Cambridge University Press. 
Kringelbach, M., \& Berridge, K. C. (2009). Towards a functional neuroanatomy of pleasure and happiness. Trends in Cognitive Sciences, 13, 479-487.

Kringelbach, M.L. \& Berridge, K.C. Functional neuroanatomy of pleasure and happiness. Discovery Medicine 9, 579-587, 2010.

Lane, R.D., McRae, K., Reiman, E.M., Chen, K., Ahern, G.L., \& Thayer, J.F. (2009). Neural correlates of heart rate variability during emotion. NeuroImage, 44, 213-222.

Lane, R.D., Reiman, E.M., Ahern, G.L., Thayer, J.F., 2001. Activity in medial prefrontal cortex correlates with vagal component of heart rate variability during emotion. Brain and Cognition 47, 97-100.

Lane, R.D., Weidenbacher, H., Fort, C.L., Thayer, J.F., Allen, J.J.B., 2008. Subgenual anterior cingulate (BA25) activity covaries with changes in cardiac vagal tone during affective set shifting in healthy adults. Psychosomatic Medicine 70, A-42.

LeDoux, J. (1996). The Emotional Brain. New York: Simon \& Schuster.

Lee, G. P., Loring, D. W., Meader, K. J., \& Brooks, B. B. (1990). Hemispheric specialization for emotional expression: A re-examination of results from intracarotid administration of sodium amobarbital. Brain and Cognition, 12, 267-280.

Levesque, J., Eugene, F., Joanette, Y., Paquette, V., Mensour, B., Beaudoin, G., et al.., 2003. Neural circuitry underlying voluntary suppression of sadness. Biological Psychiatry, $53,502-510$.

Liu, D., Diorio, J. Tannenbaum, B., Caldji, C., Francis, D., \& Freedman, A. (1997). Maternal care, hippocampal glucocorticoid receptors, and hypothalamic-pituitary-adrenal response to stress. Science, $277,1659-1662$. 
Lou, HC, Kjaer, TW, Friberg, L, Wildschiodtz, G, Holm, S, \& Nowak, M. (1999). A 15OH2O PET study of meditation and the resting state of normal consciousness. Human Brain Mapping, 7, 98-105.

Lupica, C. R., Riegel, A C., \& Hoffman, A. F. (2004). Marijuana and cannabinoid regulation of brain reward circuits. British Journal of Pharmacology, 143(2), 227-234.

Lutz, A., Greischar, L., Rawlings, N. B., Ricard, M., \& Davidson, R. J. (2004). Long-term meditators self-induce high-amplitude synchrony during mental practice, Proceedings of the National Academy of Sciences USA, 101, 16369-16373.

Lykken, D., \& Tellegen, A. (1996). Happiness is a stochastic phenomenon. Psychological Science, 7, 186-189.

Lyubomirsky, S., King, L., \& Diener, E. (2005). The benefits of frequent positive affect: Does happiness lead to success? Psychological Bulletin, 131, 803-855.

Lyubomirsky, S., Sheldon, K. M., \& Schkade, D. (2005). Pursuing happiness: The architecture of sustainable change. Review of General Psychology, 9, 111-131.

Matthews, S.C., Paulus, M.P., Simmons, A.N., Nelesen, R.A., Dimsdale, J.E., 2004. Functional subdivisions within anterior cingulate cortex and their relationship to autonomic nervous system function. NeuroImage 22, 1151-1156.

Meaney, M. J., Aitken, D. H., van Berkel, C., Bhatnagar, S., \& Sapolsky, R. M. (1988). Effect of neonatal handling on age-related impairments associated with the hippocampus. Science, 239, 766-768.

Melzig, C. A., Weike, A. I. Hamm, A. O., \& Thayer, J. F. (2009). Individual differences in fear-potentiated startle as a function of resting heart rate variability: Implications for panic disorder. International Journal of Psychophysiology, 71, 109-117. 
Merzenich, M. M. (2005). Change minds for the better. The Journal on Active Aging, 22-28.

Murphy, F.C., Nimmo-Smith, I., Lawrence, A.D. (2003) Functional neuroanatomy of emotions: a meta-analysis. Cognitive and Affective Behavioural Neurosciences, 3, $207-233$

Nes, R. B., Roysamb, E., Tambs, K., Harris, J. R. \& Reichborn-Kjennerud, T (2006). Subjective well-being: Genetic and environmental contributions to stability and change. Psychological Medicine, 36, 1033-42.

Nesse, R.M. (2004). Natural selection and the elusiveness of happiness. Philosophical Transactions of the Royal Society of London B, 359, 1333-1347.

Newberg, A.B., Wintering, N., Waldman, M.R., Amen, D., Khalsa, D.S., \& Alavi, A. (2010). Cerebral blood flow differences between long-term meditators and non-mediators. Consciousness and Cognition, 19, 899-905.

O’Doherty, J., Kringelbach, M.L., Rolls, E.T., Hornak, J., Andrews, C. (2001). Abstract reward and punishment representations in the human orbitofrontal cortex. Nature Neurosciences, 4 , 95-102.

Ochsner et al. (2002) Rethinking feelings; an fMRI study of the cognitive regulation of emotion. Journal of Cognitive Neuroscience, 14, 1215-29.

Ochsner, K. N., \& Gross, J. J. (2005). The cognitive control of emotion. Trends in Cognitive Sciences, 9, 242-9.

Ochsner, K. N., Ray, R. D., Cooper, J. C., Robertson, E. R., Chopra, S., Gabrieli, J. D. E. \& Gross, J. (2004). For better or for worse: neural systems supporting the cognitive down-and up-regulation of negative emotion. NeuroImage, 23, 483-499. 
Ochsner, K.N., \& Gross, J.J. (2004). Thinking makes it so: A social cognitive neuroscience approach to emotion regulation. In R.F. Baumeister \& K.D. Vohs (Eds). Handbook of self-regulation: Research, theory, and applications (pp. 229-255). New York: Guilford Press.

O'Connor, K., 1990. Towards a process paradigm in psychophysiology. International Journal of Psychophysiology, 9, 209-223.

Otake, K., Shimai, S., Tanaka-Matsumi, J. Otsui, K., \& Fredrickson, B. L. (2006). Happy people become happier through kindness: A counting kindness intervention. Journal of Happiness Studies, 7, 361-375.

Panksepp, J. (1998). Affective neuroscience: The foundations of human and animal emotions. Oxford University Press.

Persinger, MA, et al.. (2010). The electromagnetic induction of mystical and altered states within the laboratory. Journal of Consciousness Exploration \& Research 1 (7): 808-830

Peterson, C., Park, N., \& Seligman, M. E. (2005). Orientations to happiness and life satisfaction: The full life versus the empty life. Journal of Happiness Studies, 6, 25-41.

Phan, K.L., Wager, T., Taylor, S.F., \& Liberzon, I. (2002). Functional neuroanatomy of emotion: a meta-analysis of emotion activation studies in PET and fMRI. Neuroimage $16,331-48$.

Polk, D. E., Cohen, S., Doyle, W. J., Skoner, D. P., \& Kirschbaum, C. (2005). State and trait affect as predictors of salivary cortisol in healthy adults. Psychoneuroendocrinology, $30,261-272$.

Pressman, S.D., \& Cohen, S. (2005). Does positive affect influence health? Psychological Bulletin, 131, 925-971. 
Quirk , G. J., E. Likhtik, J. G. Pelletier, D. Paré (2003)Stimulation of medial prefrontal cortex decreases the responsiveness of central amygdala output neurons. Journal of Neuroscience, 23, 8800-8807

Quoidbach, J., Berry, E., Hansenne, M., \& Mikolajczak, M. (2010). Positive emotion regulation and well-being: Comparing the impact of eight savoring and dampening strategies. Personality and Individual Differences, 49, 368-373

Ramachandran, V. S., Hirstein, W. S., Armel, K. C., Tecoma, E. \& Iragui, V. (1997) The neural basis of religious experience. Society for Neuroscience, 23, 1316.

Reed, G. L. and Enright, R. D., (2006). The effects of forgiveness therapy on depression, anxiety, and posttraumatic stress for women after spousal emotional abuse. Journal of Consulting and Clinical Psychology, 74, 920-929.

Robinson, R.C. \& Sztela, B. (1981). Mood change following left hemisphere brain injury. Annals of Neurology, 9, 447-453.

Rosenkranz, M. A., Jackson, D. C., Dalton, K. M., Dolski, I., Ryff, C. D., Singer, B. H. et al.. (2003). Affective style and in vivo immune response: Neurobehavioral mechanisms. Proceedings of the National Academy of Sciences, 100(19), 11148-11152.

Rosenzweig, M. R. and E. L. Bennett (1996). Psychobiology of plasticity: Effects of training and experience on brain and behavior. Behavioural Brain Research, 78, 57-65.

Roysamb, E., Tambs, K., Reichborn-Kjennerud, T., Neale, M. C., \& Harris, J. R. (2003). Happiness and health: Environmental and genetic contributions to the relationship between subjective well-being, perceived health, and somatic illness. Journal of Personality and Social Psychology, 85, 1136-46. 
Ruiz-Padial, E., Sollers III, J. J., Vila, J., \& Thayer, J. F. (2003). The rhythm of the heart in the blink of an eye: Emotion-modulated startle magnitude covaries with heart rate variability. Psychophysiology, 40, 306-313.

Ryff, C.D., \& Singer, B. (1998). The contours of positive human health. Psychological Inquiry, 9, 1-28.

Ryff, C. D. (1989). Happiness is everything, or is it? Explorations on the meaning of psychological well-being. Journal of Personality and Social Psychology, 57, 1069-1081.

Ryff, C. D., Singer, B. H., \& Love, G. D. (2004). Positive health: Connecting well-being with biology. Philosophical Transactions of the Royal Society of London B, 359, 13831394.

Ryff, C.D., Love, G.D., Urry, H.L., Muller, D., Rosenkranz, M.A., Friedman, E.M., Davidson, R., \& Singer, B. (2006). Psychological well-being and ill-being: Do they have distinct or mirrored biological correlates? Psychotherapy and Psychosomatics, $75,85-95$.

Scarmeas, N. \& Y. Stern (2003). Cognitive reserve and lifestyle. Journal of Clinical and Experimental Neuropsychology, 25, 625-633.

Schaefer SM, Jackson DC, Davidson RJ, Aguirre GK, Kimberg DY, Thompson-Schill SL. (2002). Modulation of amygdalar activity by the conscious regulation of negative emotion. Journal of Cognitive Neuroscience, 14, 913-921.

Seligman, M. E. P. (2002). Authentic happiness. New York: Free Press.

Seligman, M. E. P., Steen, T. A., Park, N. P., \& Peterson, C. (2005). Positive psychology progress: Empirical validation of interventions. American Psychologist, 60, 410-421. 
Sheldon, K. M., \& Lyubomirsky, S. (2006). How to increase and sustain positive emotion: The effect of expressing gratitude and visualizing best possible selves. The Journal of Positive Psychology, 1, 73-82.

Shook, N.J., Pena, P., Fazio, R.H., Sollers, J.J., \& Thayer, J.F. (2007). Friend or foe: heart rate variability and the negativity bias in learning about novel objects, Psychophysiology, 44, S39.

Sin, N. L., \& Lyubomirsky, S. (2009). Enhancing well-being and alleviating depressive symptoms with positive psychology interventions: A practice-friendly meta-analysis. Journal of Clinical Psychology, 65, 467-487.

Smit DJA, Posthuma D, Boomsma DI, de Geus EJC. (2005). Heritability of background EEG across the power spectrum. Psychophysiology, 42, 691-697.

Smith, K.S., \& Berridge, K.C. The ventral pallidum and hedonic reward: neurochemical maps of sucrose "liking" and food intake. Journal of Neuroscience, 25, 8637-8649, 2005.

Stansbury, K., \& Gunnar, M. R. (1994). Adrenocortical activity and emotion regulation. In N. A. Fox (Ed.) The development of emotion regulation: Biological and behavioural considerations. Monographs of the Society for Research in Child Development, 59(23, Serial No. 240), 108-134.

Starkstein SE, Robinson RC, Price TR (1987). Comparison of cortical and subcortical lesions in the production of poststroke mood disorders. Brain, 110, 1045-1059.

Stewart, J., \& Vezina, P. (1988). A comparison of the effects of intra-accumbens injections of amphetamine and morphine on reinstatement of heroin intravenous selfadministration behavior. Brain Research, 457, 287-294 
Sutton, S. K. \& Davidson, R. J. (1997). Prefrontal brain asymmetry: A biological substrate of the behavioral approach and inhibition systems. Psychological Science, 8, 204-210.

Tang, Y.Y., Lu, Q., Geng, X., Stein, E.A., Yang, Y., \& Posner, M.I. (2010). Short-term meditation induces white matter changes in the anterior cingulate. Proceedings of the National Academy of Sciences of the United States of America, 107, 15649-15652.

Tang, Y.Y., Ma, Y., Fan, Y., Feng, H., Wang, J., Feng, S., . . Fan, M. (2009). Central and autonomic nervous system interaction is altered by short-term meditation. Proceedings of the National Academy of Sciences of the United States of America, $106,8865-8870$.

Tellegen, A., Lykken, DT, Bouchard, TJ, Wilcox, K, Segal, NL \& Rich, S (1988) Personality similarity in twins reared apart and together. Journal of Perosnality and Social Psychology, 54, 1031-9.

Thayer, J. F., \& Lane, R. D. (2000). A model of neurovisceral integration in emotion regulation and dysregulation. Journal of Affective Disorders, 61, 201-216.

Thayer, J. F., \& Lane, R. D. (2009). Claude Bernard and the heart-brain connection: Further elaboration of a model of neurovisceral integration. Neuroscience and Biobehavioral Reviews, 33, 81-88.

Thayer, J. F., Friedman, B. H., Borkovec, T. D., Johnsen, B. H., \& Molina, S. (2000). Phasic heart period to cued threat and non-threat stimuli in generalized anxiety disorder. Psychophysiology, 37(3), 361-8.

Thompson, R. A. (1994). Emotion regulation: A theme in search of definition. Monographs of the Society for Research in Child Development, 59, 25. 
Tomarken, A. J., Davidson, R. J., Wheeler, R. E., \& Doss, R. C. (1992). Individual differences in anterior brain asymmetry and fundamental dimensions of emotion. Journal of Personality and Social Psychology, 62, 676-687.

Urry, H. L., Nitschke, J. B., Dolski, I., Jackson, D. C., Dalton, K. M., Mueller, C. J. et al.. (2004). Making a life worth living: Neural correlates of well-being. Psychological Science, 15, 367-372.

Urry, H. L., van Reekum, C. M., Johnstone, T., Kalin, N. H., Thurow, M. E. et al.. (2006). Amygdala and ventromedial prefrontal cortex are inversely coupled during regulation of negative affect and predict the diurnal pattern of cortisol secretion among older adults. The Journal of Neuroscience, 26, 4425-4415.

Urry, H.L., vanReekum, C. M., Johnstone, T., \& Davidson, R. J. (2009). Individual differences in some (but not all) medial prefrontal regions reflect cognitive demand while regulating unpleasant emotion. NeuroImage, 47, 852-863.

van Reekum, C. M., Urry, H. L., Johnstone, T., Thurow, M. E., Frye, C. J., Jackson, C. A., et al.. (2007). Individual differences in amygdale and ventromedial prefrontal cortex activity are associated with evaluation speed and psychological well-being. Journal of Cognitive Neuroscience, 19, 237-248.

Wachtel, S.R., Ortengren, A., \& deWit, H. (2002). The effects of acute haloperidol or risperidone on subjective responses to methamphetamine in healthy volunteers. Drug Alcohol Dependence, 68, 23-33.

Wager, T.D., Phan, K.L., Liberzon, I., \& Taylor, S. (2003). Valence, gender, and lateralization of functional brain anatomy in emotion: a meta-analysis of findings from neuroimaging. NeuroImage, 19, 513-531. 
Waldstein, S.R., Kop, W.J., Schmidt, L.A., Haufler, A.J., Krantz, D.S., Fox, N.A., 2000. Frontal electrocortical and cardiovascular reactivity during happiness and anger. Biological Psychology 55, 3-23.

Waterman, A. S. (2008). Reconsidering happiness: A eudaimonist's perspective. The Journal Positive Psychology, 3, 234-252.

Watson, D., Clark, L.A., \& Tellegen, A. (1988). Development and validation of brief measures of positive and negative affect: the PANAS scales. Journal of Personality and Social Psychology, 54, 1063-70.

Wheeler, R. E., Davidson, R. J., \& Tomarken, A. J. (1993). Frontal brain asymmetry and emotional reactivity: A biological substrate of affective style. Psychophysiology, 30, 82-89.

Yu, X., Fumoto, M., Nakatani, Y., Sekiyama, T., Kikuchi, H., Seki, Y., Sato-Suzuki, I. \& Arita, H. (2011). Activation of the anterior prefrontal cortex and serotonergic system is associated with improvements in mood and EEG changes induced by Zen meditation practice in novices, International Journal of Psychophysiology, doi: 10.1016/j.ijpsycho.2011.02.004 


\section{Figure Caption}

Figure 1: Central regions implicated in well-being from A) lateral view; B) medial view. Abbreviations: NAc - Nucleus Accumbens; Am - Amygdala; Hp - Hippocampus; pHp Parahippocampal gyrus; Fp - Frontal pole; AC - Primary Auditory Cortex; VTA - Ventral tegmental area; MFB - median forebrain bundle; ; TPJ - temporal parietal junction. 
A

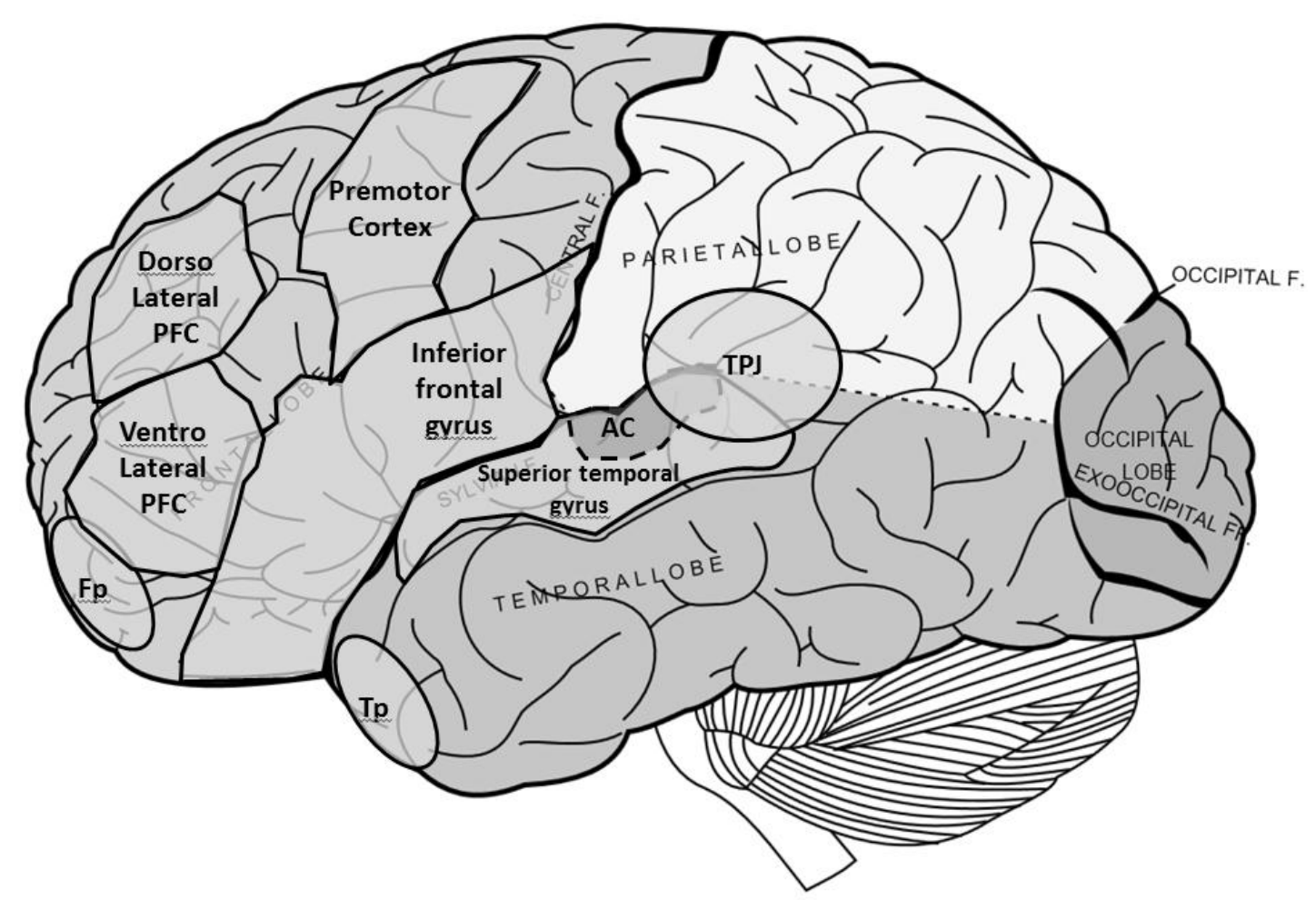

B

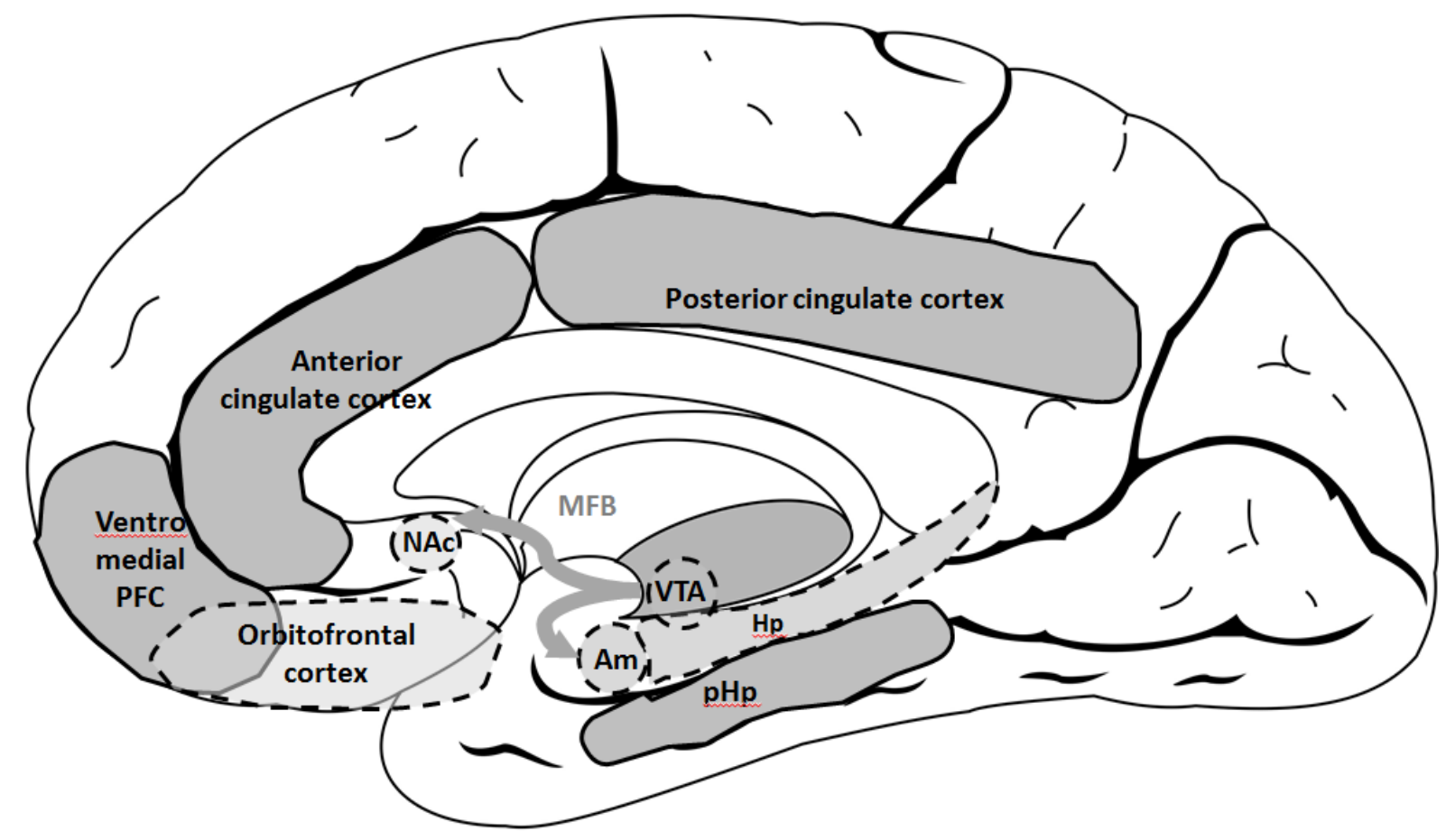




\section{University Library}

\section{- M M I N E R VA A gateway to Melbourne's research publications}

Minerva Access is the Institutional Repository of The University of Melbourne

Author/s:

Rickard, NS;Vella-Brodrick, DA

Title:

Changes in Well-Being: Complementing a Psychosocial Approach with Neurobiological Insights

Date:

2014-06-01

Citation:

Rickard, N. S. \& Vella-Brodrick, D. A. (2014). Changes in Well-Being: Complementing a Psychosocial Approach with Neurobiological Insights. SOCIAL INDICATORS RESEARCH, 117 (2), pp.437-457. https://doi.org/10.1007/s11205-013-0353-4.

Persistent Link:

http://hdl.handle.net/11343/283226 